\title{
LA INDUSTRIA Y EL COMERCIO DEL MUEBLE EN MÉXICO FURNITURE INDUSTRY AND TRADE IN MEXICO
}

\author{
Luis Enrique Espinosa Gómez* \\ Universidad Nacional Autónoma de México
}

\section{Resumen}

La industria del mueble en México exhibe carencias estructurales que no ha podido superar en las últimas décadas. La caracterización del sector es poco competitiva, muy ineficiente, el mercado interno es muy débil y la competencia de productos baratos procedentes de Asia crece más cada día que pasa. La vocación maquiladora y exportadora de México le ha permitido sortear esta problemática ya que es el tercer país que más exporta muebles a los Estados Unidos y es el país número siete por sus exportaciones al mundo. La investigación muestra la articulación de la industria del mueble con otros sectores y subsectores, se descubren las preferencias del consumidor de muebles en México por su tipo, se revela como el $13.2 \%$ de las ventas de las tiendas departamentales son muebles y se hace un diagnóstico y dimensionamiento general de la industria y el sector comercializador del mueble.

Palabras clave: mueble, industria, comercio, exportación y producción.

\section{Abstract}

The furniture industry in Mexico shows structural deficiencies which have not been overcome over the past decades. Among other reasons, those deficiencies are due to the fact that the furniture sector is uncompetitive, non-efficient, internal markets are weak and cheap Asian products are becoming more competitive. Mexico's in-bond industry and export orientation has helped dodge the problem to a certain extent, due to the fact that Mexico ranks the third largest furniture exporter to the U.S. and the seventh largest exporter worldwide. This research shows the interaction between the furniture industry and other sectors and subsectors. It also indicates consumer preferences over furniture (based on types of furniture), and also reveals that 13,2 \% of sales in department stores are related to furniture sales. Finally, a diagnosis and general dimensioning over the furniture and retail industry is made.

Keywords: furniture, industry, commerce, exports and production. 


\section{Caracterización de la industria del mueble en México y posicionamiento global}

La producción de muebles ha experimentado una muy rápida globalización en los años recientes. Esto se debe principalmente al efecto de cadenas de producción global establecidas por fabricantes y comerciantes que han buscado reducir costos en un ambiente por demás competitivo. La globalización de la industria se ha facilitado por innovaciones tecnológicas y por la reducción global de barreras a la inversión.

El Gobierno del Perú con datos al 2003 realizó un estudio donde caracteriza las industrias del mueble en Estados Unidos, Italia, España, Alemania y México. En éste se muestran las principales debilidades del clúster mueblero mexicano: Muchas empresas pequeñas que no pueden competir a escala contra grandes empresas globales; sólo seis empleados promedio por empresa con poca especialización y baja eficiencia; diversas líneas y gran variedad de diseños lo que dificulta la especialización; solo una línea de productos y pobre diversificación; poca maquinaria especializada y baja eficiencia, y una industria semi-desarrollada con capacidad instalada ociosa y bajos volúmenes de producción. Esto debilita a México en su lucha contra las importaciones, principalmente las chinas y tampoco le ayuda a aumentar su capacidad exportadora, que a pesar de todo está beneficiada fuertemente por la cercanía con los EE.UU1.

Para dimensionar la importancia y medir a las industrias del mueble, productos relacionados y de la madera con respecto al PIB total de las industrias manufactureras mexicanas, basta referirse al Banco de Información Económica (BIE) del INEGI (Instituto Nacional de Estadística y Geografía) para establecer que la industria del mueble, relativos y en de la madera en México representó el 2.21\% del promedio del PIB de toda la industria mexicana del año 2005 al 2011. El valor máximo alcanzado en este periodo fue del $2.72 \%$, mientras que el valor mínimo fue del $1.77 \%$. Medidos por separado los muebles y relativos significaron un $1.13 \%$ y la industria de la madera un $1.07 \%$ del PIB mexicano.

El PIB promedio combinado de las industrias del mueble, relacionados y de la madera en el 2001 fue en miles de pesos $\$ 39,944,082$, en el 2005 alcanzó $\$ 41$, 359,801 y en el 2011 cerró con $\$ 49,970,222$. En el quinquenio 2001 al 2005 el crecimiento fue un pobre $3.54 \%$ con un promedio del $0.68 \%$ anual. Del 2006 al 2011 el crecimiento total fue del $20.8 \%$ lo que implicó un crecimiento anual del 2.97\%. Del 2001 al 2011 el crecimiento fue del $25.1 \%$ equivalente a solo un $2.28 \%$ anual $^{2}$.

El PIB promedio de toda la industria en miles de pesos en el 2001 fue de $\$ 1,260,287,656$. En el 2005 totalizó $\$ 1,629,679,202$ y en el 2011 sumó $\$ 2,495$, 012,410. En el quinquenio 2001 al 2005 el crecimiento fue del 29.3\%, equivalente a un $5.86 \%$ anual, cifra $827 \%$ superior al crecimiento promedio anual de las industrias del mueble, relativos y de la madera. Del 2005 al 2011 el crecimiento en la industria total fue del $53.09 \%$, equivalente al $7.58 \%$ anual y $211.5 \%$ mayor que la industria del mueble, relacionados y de la madera. Del 2001 al 2011 el 
crecimiento de toda la industria fue del 97.9\% equivalente al 8.9\% anual.

La industria del mueble, relativos y de la madera en México está en crisis. Del 2001 al 2011 e observó un crecimiento de sólo un 25.1\%, equivalente a un $2.28 \%$ del promedio anual (INEGI), cuando la media de la industria total creció un $97.9 \%$ en este periodo de bonanza para un promedio anual del 8.9\%. Esto es, la industria mexicana total creció 3.9 veces más que la del mueble.

\begin{tabular}{|c|c|c|c|c|c|}
\hline Variable & EEUU & Italia & España & Alemania & México \\
\hline \multirow{2}{*}{$\begin{array}{l}\text { Tamaño de } \\
\text { empresas }\end{array}$} & $\begin{array}{l}\text { Grandes y } \\
\text { medianas }\end{array}$ & $\begin{array}{l}\text { Gran número } \\
\text { de empresas, } \\
\text { principalmente } \\
\text { pequeñas }\end{array}$ & $\begin{array}{l}\text { Gran número } \\
\text { de empresas, } \\
\text { principalmente } \\
\text { pequeñas }\end{array}$ & $\begin{array}{l}\text { Pocas empresas } \\
\text { grandes }\end{array}$ & $\begin{array}{l}\text { Muchas } \\
\text { empresas } \\
\text { pequeñas }\end{array}$ \\
\hline & $\begin{array}{l}70 \text { personas } \\
\text { promedio por } \\
\text { empresa }\end{array}$ & $\begin{array}{l}5 \text { a } 10 \text { personas } \\
\text { por empresa }\end{array}$ & $\begin{array}{l}6 \text { a } 10 \text { personas } \\
\text { por empresa }\end{array}$ & $\begin{array}{l}80 \text { a } 100 \\
\text { personas por } \\
\text { empresa }\end{array}$ & $\begin{array}{l}6 \text { a } 7 \text { personas } \\
\text { promedio por } \\
\text { empresa }\end{array}$ \\
\hline Estilo & $\begin{array}{l}\text { Funcional con } \\
\text { diseños que } \\
\text { cambian cada } 5 \\
\text { años }\end{array}$ & $\begin{array}{l}\text { Muebles de } \\
\text { diseño artístico } \\
\text { y vanguardia }\end{array}$ & $\begin{array}{l}\text { Muebles de } \\
\text { diseño artístico } \\
\text { y estético, } \\
\text { funcionables y } \\
\text { durables }\end{array}$ & $\begin{array}{l}\text { Muebles de alta } \\
\text { calidad en su } \\
\text { manufactura, } \\
\text { funcional y } \\
\text { durable }\end{array}$ & $\begin{array}{l}\text { Diversas líneas } \\
\text { con gran } \\
\text { variedad de } \\
\text { modelos } \\
\text { dentro de cada } \\
\text { una }\end{array}$ \\
\hline $\begin{array}{l}\text { Línea de } \\
\text { productos }\end{array}$ & $\begin{array}{l}\text { Pocas líneas con } \\
\text { variedad de } \\
\text { modelos dentro de } \\
\text { cada una }\end{array}$ & $\begin{array}{l}\text { Muchas líneas } \\
\text { con gran } \\
\text { variedad de } \\
\text { productos }\end{array}$ & $\begin{array}{l}\text { Muchas líneas } \\
\text { y gran variedad } \\
\text { de productos, } \\
\text { pero menos } \\
\text { que en Italia }\end{array}$ & $\begin{array}{l}\text { Pocas líneas y } \\
\text { poca variedad de } \\
\text { modelos }\end{array}$ & Una \\
\hline $\begin{array}{c}\text { Maquinaria y } \\
\text { equipo }\end{array}$ & $\begin{array}{l}\text { Especializada y } \\
\text { con equipo de } \\
\text { control numérico }\end{array}$ & $\begin{array}{l}\text { Maquinaria } \\
\text { sofisticada }\end{array}$ & $\begin{array}{l}\text { Maquinaria } \\
\text { sofisticada }\end{array}$ & $\begin{array}{l}\text { Maquinaria más } \\
\text { especializada y } \\
\text { de mayor } \\
\text { complejidad }\end{array}$ & $\begin{array}{l}\text { Poca } \\
\text { maquinaria } \\
\text { especializada, } \\
\text { equipo semi } \\
\text { industrial }\end{array}$ \\
\hline $\begin{array}{l}\text { Tipo de } \\
\text { industria }\end{array}$ & $\begin{array}{l}\text { Muy desarrollada, } \\
\text { con capacidad } \\
\text { para producir } \\
\text { grandes } \\
\text { volúmenes }\end{array}$ & $\begin{array}{l}\text { Mucho oficio, } \\
\text { prestigio y } \\
\text { tradición } \\
\text { familiar. } \\
\text { Imagen } \\
\text { artesanal }\end{array}$ & $\begin{array}{l}\text { Mucho oficio, } \\
\text { prestigio y } \\
\text { tradición } \\
\text { familiar }\end{array}$ & $\begin{array}{l}\text { Industria muy } \\
\text { desarrollada y de } \\
\text { gran escala }\end{array}$ & $\begin{array}{l}\text { Semi } \\
\text { desarrollada, } \\
\text { con capacidad } \\
\text { instalada } \\
\text { ociosa. Bajos } \\
\text { volúmenes }\end{array}$ \\
\hline
\end{tabular}

Fig. 1. Caracterización de la industria del mueble. Fuente extraída de BANCOMEXT, Oficina de Cooperación y Negocios Internacionales de CANACO, "Caracterización de la Industria del Mueble", en Perfil de Mercado y Competitividad Exportadora de Muebles de Madera, Gobierno del Perú, 2003, p. 26.

\section{El comercio exterior de muebles, productos relacionados al mismo y de la madera en México}

Para situar al comercio exterior de México en muebles, maderas y relativos a los mismos, se consultó el Anuario Estadístico del Comercio Exterior de los Estados Unidos Mexicanos del $2010^{3}$.

En la fracción correspondiente a muebles, mobiliario médico-quirúrgico, artículos de cama y similares, aparatos de alumbrado no expresados ni comprendidos en otra parte, anuncios, letreros y placas indicadoras, luminosos y 
artículos similares y construcciones prefabricadas, se encontró que por vía aérea, las exportaciones mexicanas fueron de \$28, 126,000 dólares y las importaciones de $\$ 45,124,000 \mathrm{Usd}$, con una balanza deficitaria de $(\$ 16,998,000)$ Usd. Por vía marítima, las exportaciones mexicanas sumaron $\$ 147,590,000$ Usd, las importaciones $\$ 839,927,000$ Usd con una balanza deficitaria de $(\$ 692,337,000)$ Usd. Por transporte ferroviario, las exportaciones mexicanas sumaron $\$ 9$, 225,000 Usd y las importaciones fueron de $\$ 41,558,000 \mathrm{Usd}$, para causar una balanza deficitaria de $(\$ 32,333,000)$ Usd. Por carretera las exportaciones mexicanas sumaron $\$ 5,204,226,000$ Usd y las importaciones alcanzaron $\$ 1,297$, 205,000 Usd, lo que significó una balanza superavitaria de $\$ 3,907,021,000$ Usd. Por otros medios de transporte, las exportaciones mexicanas sumaron \$27, 377,000 Usd mientras que las importaciones alcanzaron $\$ 47,739,000$ Usd, igual a una balanza deficitaria de $(\$ 20,362,000)$ Usd.

En muebles la balanza comercial fue superavitaria por $\$ 3,161,972,002$ Usd debido principalmente al transporte carretero de exportaciones a los EE.UU., destino primario de la fabricación mexicana para la exportación y maquila de muebles desde México. En la fracción madera, carbón vegetal y manufacturas de madera se encontró que por vía aérea, las exportaciones mexicanas fueron de $\$ 574,000$ Usd y las importaciones $\$ 3,926,000$ Usd con una balanza deficitaria de $(\$ 3,352,000)$ Usd. Por vía marítima, las exportaciones mexicanas sumaron $\$ 14,249,000$ Usd y las importaciones $\$ 550,854,000$ Usd, arrojando una balanza deficitaria de $(\$ 536,605,000)$ Usd. Por transporte ferroviario, las exportaciones mexicanas sumaron $\$ 1,865,000$ Usd y las importaciones ascendieron a $\$ 115,830,000 \mathrm{Usd}$, igual a una balanza deficitaria de $(\$ 113,965,000)$ Usd. Por carretera las exportaciones mexicanas sumaron $\$ 271$, 088,000 Usd y las importaciones $\$ 491,122,000$ Usd arrojando una balanza deficitaria de $(\$ 220,034,000)$ Usd. Por otros medios de transporte, las exportaciones mexicanas sumaron $\$ 383,000$ Usd y las importaciones alcanzaron $\$ 13,598,000$ Usd, para arrojar una balanza deficitaria de $(\$ 13,215,000)$ Usd.

En total en la industria de la madera la balanza F.O.B. (Free On Board) fue deficitaria por todos los medios de transporte en un importe de $\$ 887,171,000$ dólares. Al sumar las balanzas comerciales del mueble y de la madera arroja un superávit de $\$ 3,019,850,000$ Usd, lo cual es muy positivo si se considera que la industria en total en el 2010 exportó $\$ 298,473,146,000$ Usd y México importó $\$ 301,481,819,000 \mathrm{Usd}$, lo que arroja un déficit de $\$ 3,008,673$ equivalente al (1.0\%) del PIB.

A pesar de la relevancia de la balanza superavitaria en el mueble y de que las exportaciones del mueble representan el 1.80\% del total exportado por el país, internamente hay pesimismo porque, aunque el mercado externo crece muy bien, el mercado interno es débil y no crece al ritmo de la economía nacional.

Externamente México ocupa un lugar relevante por ser un país altamente exportador de muebles a los Estados Unidos. En el 2005, México fue el tercer país en importancia como exportador de muebles a los EE.UU. que compró en la nación mexicana el $12.7 \%$ del total de sus importaciones de muebles, observando la parte exportadora un crecimiento anual dinámico promedio del $10.4 \%$. 


\begin{tabular}{|c|c|c|c|c|c|}
\hline $\begin{array}{c}\text { País } \\
\text { exportador }\end{array}$ & $\begin{array}{c}\text { Importaciones } \\
2005\end{array}$ & $\%$ & $\begin{array}{c}\text { Importaciones } \\
1996\end{array}$ & $\%$ & $\begin{array}{c}\text { Cambio \% } \\
\text { Promedio } \\
\text { Anual } 1996 \\
\text { al } 2005\end{array}$ \\
\hline China & $15,479.90$ & 45.5 & $1,478.60$ & 12.8 & 29.8 \\
\hline Canadá & $5,202.60$ & 15.3 & $3,411.40$ & 29.6 & 4.8 \\
\hline México & $4,334.00$ & 12.7 & $1,779.30$ & 15.4 & 10.4 \\
\hline Italia & $1,185.80$ & 3.5 & 858.9 & 7.4 & 3.6 \\
\hline Malasia & 908 & 2.7 & 500.2 & 4.3 & 6.8 \\
\hline Vietnam & 850.1 & 2.5 & 0.4 & 0 & 134.8 \\
\hline Taiwán & 801.9 & 2.4 & $1,213.20$ & 10.5 & -4.5 \\
\hline Indonesia & 729.5 & 2.1 & 311.8 & 2.7 & 9.9 \\
\hline Tailandia & 531.7 & 1.6 & 220.7 & 1.9 & 10.3 \\
\hline Brasil & 529.9 & 1.6 & 74.6 & 0.6 & 24.3 \\
\hline Alemania & 365.5 & 1.1 & 157.8 & 1.4 & 9.8 \\
\hline Filipinas & 330.7 & 1 & 222.1 & 1.9 & 4.5 \\
\hline $\begin{array}{l}\text { Reino } \\
\text { Unido }\end{array}$ & 254.2 & 0.7 & 195.5 & 1.7 & 3 \\
\hline Francia & 237.3 & 0.7 & 82.1 & 0.7 & 12.5 \\
\hline India & 233.4 & 0.7 & 28.5 & 0.2 & 26.3 \\
\hline Otros & $2,043.20$ & 0.060 & $1,009.20$ & 0.089 & \\
\hline $\begin{array}{l}\text { Total } \\
\text { Mundial }\end{array}$ & $34,017.70$ & 100 & $11,544.30$ & 100 & 12.8 \\
\hline
\end{tabular}

Fig. 2. Países exportadores de muebles a los EE.UU. de 1996 al 2005 (en millones de dólares). DRAYSE, Mark, "Globalization and Regional Change in the U.S. Furniture Industry", en Growth \& Change, vol. 39(2), 2008, p. 258.

Se observa que de 1996 a 2005 los países con crecimientos porcentuales anuales promedio más altos que el $10.4 \%$ de México fueron Vietnam con $134.8 \%$, China con $29.8 \%$ e India con $26.3 \%$. Es importante señalar que México cayó en su proporción exportadora de muebles a los EE.UU., pasando del 15.4\% en 1996 al $12.7 \%$ en el 2005. El PIB del mueble, relativos y de la madera creció en promedio del 2001 al 2005 un $0.68 \%$ anual en México, pero las exportaciones a EE.UU. crecieron un 10.4\% promedio de 1996 al 2005. Se concluye que México tiene un mercado interno muy débil y una infraestructura exportadora a los EE.UU. fuerte y dinámica.

Dentro del contexto mundial es relevante observar cual es la importancia de México como país exportador. 


\begin{tabular}{|l|r|r|r|}
\hline País & \multicolumn{1}{|c|}{$\begin{array}{c}\text { Exportaciones } \\
\text { millones USD } \\
2005\end{array}$} & $\begin{array}{c}\text { Porcentaje } \\
\text { respecto al } \\
\text { mundo }\end{array}$ & $\begin{array}{c}\text { Cambio } \\
\text { promedio } \\
\text { porcentual } \\
1999-2005\end{array}$ \\
\hline China & $16,571,814$ & 17.5 & 29.8 \\
\hline Italia & $10,538,493$ & 11.1 & 3.8 \\
\hline Alemania & $7,574,119$ & 8.0 & 6.9 \\
\hline Canadá & $5,641,650$ & 5.9 & 3.4 \\
\hline Polonia & $5,551,047$ & 5.9 & 19.0 \\
\hline Estados Unidos & $5,190,359$ & 5.5 & 3.0 \\
\hline México & $4,559,805$ & 4.8 & 12.2 \\
\hline Francia & $2,970,609$ & 3.1 & 3.2 \\
\hline Dinamarca & $2,650,578$ & 2.8 & 5.4 \\
\hline Bélgica & $2,141,769$ & 2.3 & 2.4 \\
\hline Malasia & $2,024,695$ & 2.1 & 6.4 \\
\hline República Checa & $1,902,976$ & 2.0 & 16.7 \\
\hline España & $1,874,510$ & 2.0 & 4.1 \\
\hline Indonesia & $1,856,060$ & 2.0 & 7.0 \\
\hline Austria & $1,804,620$ & 1.9 & 9.0 \\
\hline Otros & & 23.1 & \\
\hline Países industrializados & $50,592,183$ & 53.4 & 5.1 \\
\hline Países en transición & $13,730,457$ & 14.5 & 17.5 \\
\hline Nuevos industrializados & $29,423,865$ & 31.0 & 18.6 \\
\hline Subdesarrollados & $1,078,430$ & 1.1 & 7.9 \\
\hline Total mundial & $94,824,935$ & & \\
\cline { 1 - 3 } & & & \\
& & & \\
\hline
\end{tabular}

Fig. 3. Exportación mundial global de muebles de 1999 al 2005. DRAYSE, Mark, "Globalization and Regional Change in the U.S. Furniture Industry”, en Growth \& Change, vol. 39(2), 2008, p. 262.

Entre 1999 y 2005 el crecimiento promedio del 12.2\% anual de México como país exportador de muebles superó al PIB del mueble, relativos y de la madera que creció anualmente $5.68 \%$ en promedio en este periodo. A nivel mundial en el 2005 fue el séptimo exportador de muebles con $\$ 4,559,805,000$ Usd. En el 2010 el INEGI reporta en el Anuario Estadístico del año exportaciones por $\$ 5,416,544,755$ Usd o un $18.78 \%$ de crecimiento en el quinquenio 2005 a 2010 y un crecimiento promedio anual de solo $3.75 \%$. Debe ser tenido en cuenta que del 1996 al 2005 las exportaciones de mueble crecieron un promedio anual de un $12.2 \%$, siendo la razón principal de la desaceleración la crisis económica global acontecida entre 2007 y 2010.

En el contexto económico global es importante tener en cuenta la articulación de la industria del mueble y de la madera con otras actividades económicas. La industria del mueble se vincula en última instancia con el sector forestal que proporciona la materia prima principal (la madera). Asimismo se 
relaciona con el sector agrícola, el manufacturero y con los subsectores de fabricación de cuchillería, herramientas de mano, ferretería, pinturas, barnices y otros productos de revestimiento. Hacia adelante la industria del mueble se vincula con el comercio por los bienes de consumo que produce para el mismo y con el sector de la construcción, como se ve en la siguiente figura.

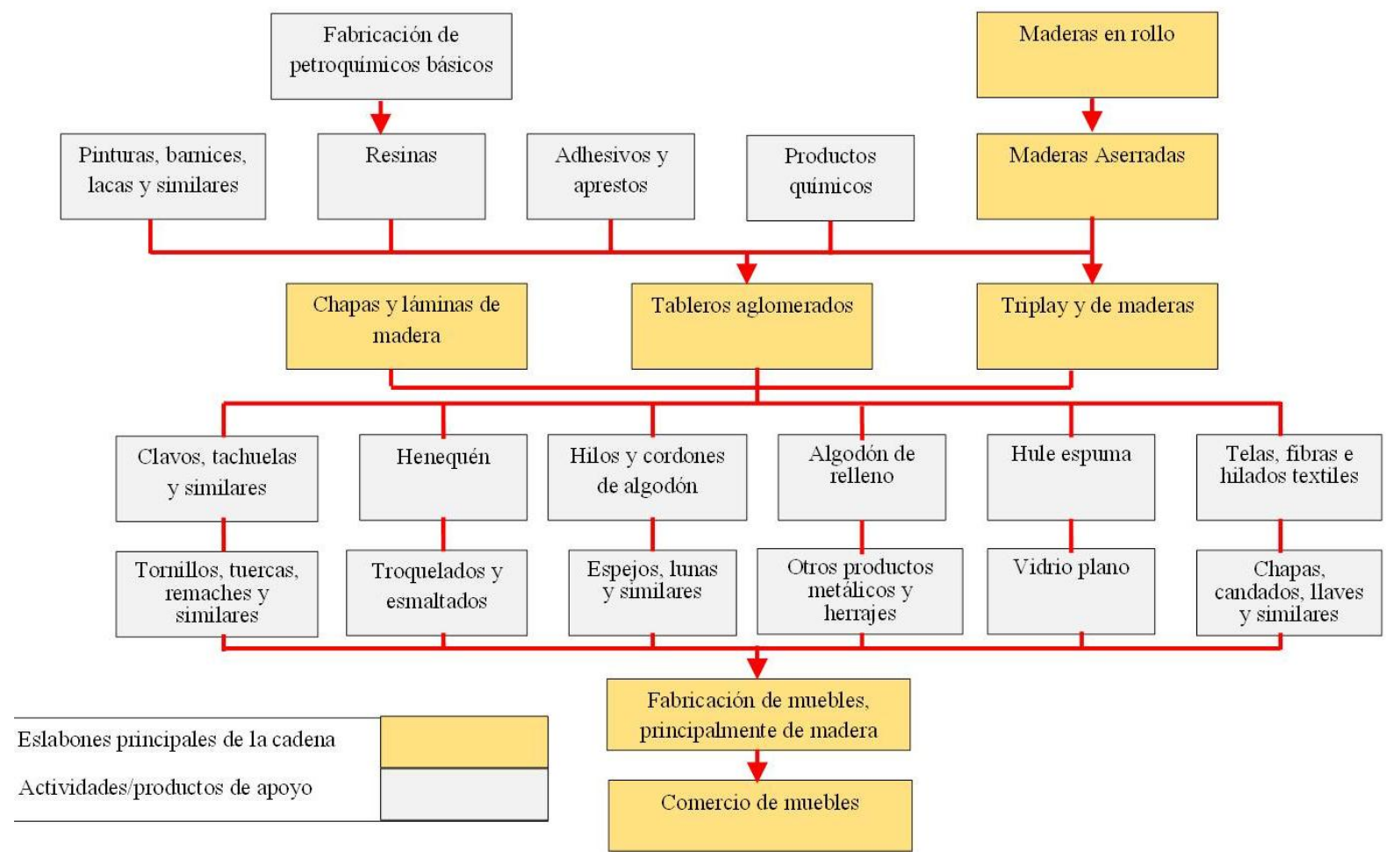

Fig. 4. Vinculación de la industria del mueble y de la madera con otras actividades económicas en EE.UU., Italia, España, Alemania y México. GOBIERNO DEL PERÚ, Perfil de Mercado y Competitividad Exportadora de Muebles de Madera, minicetur.gob.pe, 2003, p.8.

\section{Comercio al por menor de muebles y artículos de decoración en México: productos y puntos de venta}

Los indicadores principales del sector comercial del mueble y de la madera se obtienen del Censo Económico del INEGI del 2004 (Fig. 5) y estadísticas del mismo publicadas desde el 2006 en el cuadro COMEP 01 (Características Principales de los Establecimientos de Comercio al Por Menor)4. Esta publicación cumplió el objetivo de conocer las motivaciones y preferencias de compra del consumidor mexicano de muebles según su tipo. La información se obtuvo del INEGI (Fig.6).

Las recámaras sobrepasan a otros tipos de muebles como los más consumidos con un $31.87 \%$ del total, las salas le siguen con un lejano $19.27 \%$ y después los comedores con un $17.63 \%$. El mayor consumo de recámaras se explica porque estas son compradas para su uso por pareja o de modo individual mientras que los comedores y las salas son comprados para el uso de toda la familia. Es claro como la estadística mexicana muestra la imperiosa necesidad de la 
compra de recámaras antes que cualquier otro tipo de mueble. En cada sociedad, país y región existen diferentes patrones y motivaciones de consumo de muebles. En los países de la Unión Europea se venden más las salas con un 16\%, las cocinas le siguen con $15 \%$ y después los dormitorios $(12 \%)$.

El $1.7 \%$ de los establecimientos totales;

El 2.42\% del personal ocupado;
El $4.03 \%$ de los establecimientos grandes.

El 2.7\% del personal ocupado por establecimientos grandes;

El $1.96 \%$ del total de la mercancía comprada para su reventa.

Fig. 5. Proporción en factores clave del comercio de muebles y maderas con el comercio total (2004). ESPINOSA GÓMEZ, Luis, La industria y el comercio del mueble en México, UNAM, 2012, p. 20.

\begin{tabular}{|l|r|r|r|r|r|}
\hline \multirow{2}{*}{$\begin{array}{l}\text { Clase de actividad y } \\
\text { tipo de producto }\end{array}$} & \multicolumn{2}{|c|}{$\begin{array}{r}\text { Ventas netas de mercancías } \\
\text { (Miles de pesos) }\end{array}$} & \multirow{2}{*}{$\begin{array}{c}\text { Margen } \\
\text { comercial } \\
\text { promedio }\end{array}$} & $\begin{array}{c}\text { Porcentaje } \\
\text { de } \\
\text { importancia }\end{array}$ \\
\cline { 2 - 4 } & \multicolumn{1}{|c|}{ Total } & \multicolumn{2}{|c|}{ Mercado } \\
\cline { 2 - 4 } & $\mathrm{A}=\mathrm{B}+\mathrm{C}$ & $\begin{array}{c}\text { Nacional } \\
\text { - B - }\end{array}$ & $\begin{array}{c}\text { Extranjero } \\
-\mathrm{C}-\end{array}$ & $25-29$ & $100.0 \%$ \\
\hline $\begin{array}{l}\text { Muebles para el hogar: (dentro de } \\
\text { clase 455111) }\end{array}$ & $7,793,386$ & $7,788,806$ & 4,580 & - & $31.87 \%$ \\
\hline Recámaras, literas y cunas & $2,483,583$ & $2,481,702$ & 1,881 & 27 & $19.27 \%$ \\
\hline Salas & $1,502,090$ & $1,501,945$ & 145 & 27 & $17.63 \%$ \\
\hline Comedoresy antecomedores & $1,374,322$ & $1,371,840$ & 2,482 & 25 & $14.91 \%$ \\
\hline $\begin{array}{l}\text { Sillas, sillones, reposets y sofás- } \\
\text { cama }\end{array}$ & $1,162,096$ & $1,162,096$ & 0 & 27 & $2.95 \%$ \\
\hline Bases para colchón & 230,253 & 230,253 & 0 & 29 & $2.85 \%$ \\
\hline Juegos de mesas & 222,359 & 222,287 & 72 & 27 & $2.91 \%$ \\
\hline Roperos y similares & 226,583 & 226,583 & 0 & 27 & $3.95 \%$ \\
\hline $\begin{array}{l}\text { Centros de entretenimiento y } \\
\text { similares }\end{array}$ & 307,466 & 307,466 & 0 & 26 & $3.13 \%$ \\
\hline Libreros & 244,300 & 244,300 & 0 & 26 & $0.52 \%$ \\
\hline Otros & 40,334 & 40,334 & 0 & 26 & $100 \%$ \\
\hline $\begin{array}{l}\text { Porcentaje contra la actividad } \\
\text { subsector muebles y relativos }\end{array}$ & $100 \%$ & $100 \%$ & $100 \%$ & & 27 \\
\hline
\end{tabular}

Fig. 6. Venta de muebles por tipo de producto en México en 2006. ESPINOSA GÓMEZ, Luis, La industria y el comercio del mueble en México, UNAM, 2012, p. 20.

Otro de los aspectos analizados con respecto al comercio de muebles al por menor fue el de los establecimientos de venta al público. En el comercio al por menor de muebles, el importe de las ventas netas de todos los productos en tiendas departamentales de acuerdo al INEGI en el Censo Económico del 2004 fue de $\$ 71,242,605,000$ pesos $^{5}$. El comercio de muebles y relativos según la clase 4622190 en tiendas departamentales sumó $\$ 9,382,087$ pesos, lo que representa un $13.2 \%$ del total. 


\section{Muebles $11.6 \%$ - Blancos y telas $1.1 \%$ - Artículos para la decoración de interiores $0.5 \%$}

Fig. 7. Composición a detalle de la mezcla de ventas de muebles y relacionados del $13.2 \%$ en tiendas departamentales. ESPINOSA, Op. Cit, p. 21.

Del Censo Económico del 2004 publicado en el 2006 por el INEGI, se extrajeron determinados indicadores de los subsectores combinados de los muebles para el hogar, alfombras, tapices, lámparas y artículos para la decoración, para compararlos con el sector comercial en su totalidad, lo que permite dimensionar al sector comercial del mueble y relativos con respecto a los grandes totales nacionales. A través de los indicadores considerados como más relevantes podemos deducir el posicionamiento del comercio al por menor mexicano en el sector.

En el número de establecimientos comerciales al por menor, los sectores del mueble y relativos representan el $1.7 \%$ del total de los puntos de venta con 25,433 unidades, contra un total nacional de 1, 493,590. En establecimientos grandes representan el $4.0 \%$ con 1,983 unidades contra un total nacional de $49,147$.

Se da empleo en comercios de muebles y relativos al por menor a 97,756 personas de un total de 4, 035,223 en todo el comercio al por menor en México, bueno para un $2.4 \%$ del total empleado. En establecimientos grandes se emplea a 30,091 personas en muebles y relativos contra un total de 1, 113,379 gentes equivalente al $2.63 \%$ del personal.

Se compra el 1.9\% del total de la mercancía con objeto de revenderla. En establecimientos grandes la compra de mercancía para su reventa fue del $1.6 \%$. Las ventas netas de mercancías de muebles y relativos para su reventa alcanzaron el 2.2\%. En establecimientos grandes, las ventas netas de mercancías para su reventa alcanzaron el 1.9\%. El valor de los activos fijos sumó el $2.4 \%$ del total. En establecimientos grandes el valor de los activos fijos sumó el $1.7 \%$ del total.

\section{Análisis de los índices de ventas netas, comerciales e industriales en el comercio al por menor de muebles y artículos de decoración}

No se deben ignorar los últimos datos estadísticos sobre el desempeño de las actividades principales de los subsectores de muebles y relacionados ${ }^{6}$. El análisis se realizó seleccionando los índices que se consideraron más importantes.

En muebles y enseres domésticos, el índice de ventas netas cayó en términos reales del 2007 al 2009 un 24.33\%, lo que marca el fiel reflejo de una fuerte contracción del mercado interno, ya que del 2003 al 2009 la retracción fue del $21.9 \%$. En el subsector artículos de decoración la caída del índice de ventas netas del 2007 al 2009 fue del 10\%, mientras que en el conjunto del periodo del 
2003 al 2009 hubo un crecimiento del 16.0\%. Las caídas en ambos índices del 2007 al 2009 se explican por la alta contracción del mercado debido a la crisis mundial del 2007 al 2010 ya mencionada.

En muebles y enseres domésticos, el índice de personal ocupado en el comercio al por menor cayó en términos reales del 2007 al 2009 un 19.73\%, menos que en el periodo del 2003 al 2009 en el que el tamaño de la contracción alcanzó la altísima cifra del $34.22 \%$. En artículos para la decoración el índice de personal empleado del 2007 al 2009 creció un 1.37\%, mostrando entre el 2003 y el 2009 (mostró) un crecimiento total del 10.2\% ${ }^{7}$. La pérdida de empleos en el subsector del mueble en México, fue expuesta desde el 22 de enero del 2004 por el entonces presidente del Ramo Mueblero de la Canacintra, Manuel Vázquez Arias, que calculó la reducción del $20 \%$ de la planta productiva en el periodo comprendido de 1999 al $2004^{8}$.

Además es necesario conocer la importancia en número de establecimientos industriales en México por subsector y observar la posición que ocupan las industrias del mueble y de la madera. Por lo tanto, se recabo el número de establecimientos industriales de distintas ramas, sectores y subsectores industriales ${ }^{9}$.

\begin{tabular}{|l|l|c|c|c|c|}
\hline $\begin{array}{l}\text { Sub- } \\
\text { sector }\end{array}$ & \multicolumn{1}{|c|}{$\begin{array}{c}\text { Número de } \\
\text { Establecimientos }\end{array}$} & $\begin{array}{c}\% \text { del } \\
\text { Total }\end{array}$ & $\begin{array}{c}\text { Lugar en } \\
\text { Importancia }\end{array}$ & $\begin{array}{c}\% \\
\text { Acumulado }\end{array}$ \\
\hline 311 & Alimentaria & 995 & $15.02 \%$ & 1 & $15.02 \%$ \\
\hline 327 & Productos con minerales no metálicos & 595 & $8.98 \%$ & 2 & $24.00 \%$ \\
\hline 326 & Plástico y hule & 567 & $8.56 \%$ & 3 & $32.55 \%$ \\
\hline 325 & Industria química & 523 & $7.89 \%$ & 4 & $40.45 \%$ \\
\hline 315 & Prendas de vestir & 499 & $7.53 \%$ & 5 & $47.98 \%$ \\
\hline 321 y & Madera y Muebles & 439 & $6.63 \%$ & 6 & $54.61 \%$ \\
\hline 337 & Productos metálicos & 413 & $6.23 \%$ & 7 & $60.84 \%$ \\
\hline 332 & 374 & $5.64 \%$ & 8 & $66.49 \%$ \\
\hline 336 & Euero sin prendas de vestir & 319 & $4.81 \%$ & 9 & $71.30 \%$ \\
\hline 333 & Maquinaria y equipo & 305 & $4.60 \%$ & 10 & $75.90 \%$ \\
\hline 339 & Otras industrias & 251 & $3.79 \%$ & 11 & $79.69 \%$ \\
\hline 322 & Industria del papel & 238 & $3.59 \%$ & 12 & $83.28 \%$ \\
\hline 313 & Insumos textiles & 216 & $3.26 \%$ & 13 & $86.54 \%$ \\
\hline 331 & Metálicas básicas & 215 & $3.24 \%$ & 14 & $89.79 \%$ \\
\hline 312 & Bebidas y del tabaco & 155 & $2.34 \%$ & 15 & $92.13 \%$ \\
\hline 323 & Impresión y conexas & 149 & $2.25 \%$ & 16 & $94.38 \%$ \\
\hline 335 & $\begin{array}{l}\text { Generación eléctrica y aparatos } \\
\text { eléctricos }\end{array}$ & 146 & $2.20 \%$ & 17 & $96.58 \%$ \\
\hline 314 & Productos textiles sin prendas de vestir & 110 & $1.66 \%$ & 18 & $98.24 \%$ \\
\hline 334 & $\begin{array}{l}\text { Equipo de computación, comunicación } \\
\text { y medición }\end{array}$ & 59 & $0.89 \%$ & 19 & $99.13 \%$ \\
\hline 324 & Derivados del petróleo y del carbón & 58 & $0.88 \%$ & 20 & $100.00 \%$ \\
\hline & TOTAL & 6,626 & $100.00 \%$ & & \\
\cline { 2 - 5 } & & & & \\
\hline
\end{tabular}

Fig. 8. Establecimientos industriales en México por subsector. ESPINOSA... Op. Cit., p. 23. 
Sumados los subsectores del mueble y de la madera, el número de establecimientos industriales alcanza un total de 439 unidades, equivalente al sexto lugar en importancia a nivel nacional y bueno para un 6.63\%. Existen 121 subsectores de la industria del mueble y de la madera que no fueron considerados por el INEGI en la tabla anterior. Estos son alfombras, blancos y similares con 41 establecimientos, adhesivos y selladores con 27 , muebles de baño con 16 , herrajes y cerraduras con 10, maquinaria y equipo para la industria de la madera con 8 y lámparas ornamentales con 19. Sumando estos 121 establecimientos industriales con los 439 establecimientos de los muebles y de la madera recién anotados, se concluye que el sector del mueble, la madera y la decoración suma 560 establecimientos industriales, equivalentes a un $8.45 \%$ del total. Para medir a la industria del mueble y de la madera frente al total de la industria mexicana, se usó la Encuesta Industrial Anual 2007-2008 del INEGI ${ }^{10}$.

\begin{tabular}{|l|r|r|r|}
\hline Variable & \multicolumn{1}{|c|}{ Total } & \multicolumn{1}{|c|}{$\begin{array}{c}\text { Industria del } \\
\text { Mueble y la } \\
\text { madera }\end{array}$} & Porcentaje \\
\hline Número de personas & $1,516,000$ & 61,864 & $4.08 \%$ \\
\hline Remuneraciones promedio por persona & $\$ 170,838$ & $\$ 98,605$ & $57.72 \%$ \\
\hline Producción bruta total por persona ocupada & $\$ 2,347,489$ & $\$ 1,158,415$ & $49.35 \%$ \\
\hline Insumos totales por persona ocupada & $\$ 1,653,281$ & $\$ 820,070.17$ & $49.60 \%$ \\
\hline Valor agregado bruto por persona ocupada & $\$ 694,208$ & $\$ 338,345.13$ & $48.74 \%$ \\
\hline
\end{tabular}

Fig. 9. Indicadores industria del mueble y la madera contra la industria total. ESPINOSA, Op. Cit. p.24.

Las industrias del mueble y de la madera emplearon al 4.08\% del personal total empleado por toda la industria mexicana. A este total habría que sumarle los cerca de 100,000 empleados del mueble y relativos que trabajan en su comercio, lo que arroja un aproximado de 160,000 empleos directos. Resaltar el dato de gente empleada en la industria del mueble y de la madera, que contabilizó al final del 2008 a 61,864 personas de un total de 1, 516,000 personas empleadas en toda la industria en México.

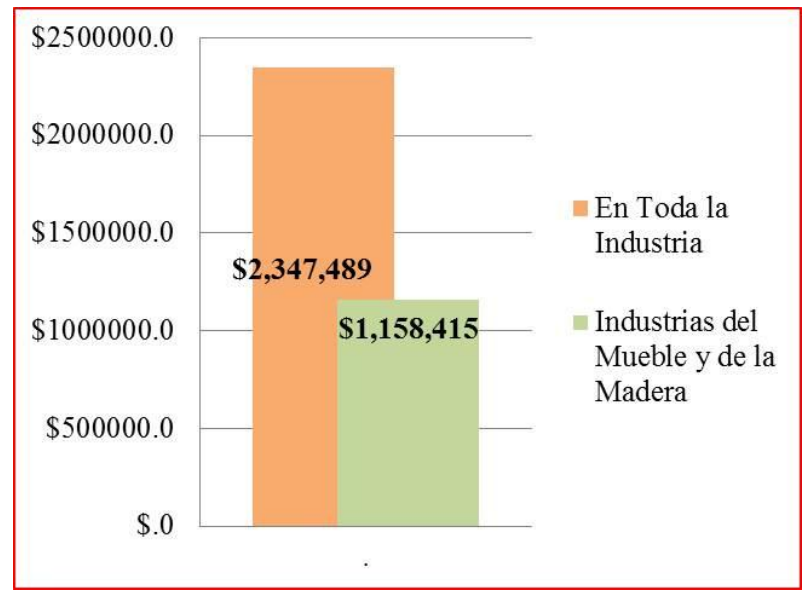

Fig. 10. Producción bruta total por persona ocupada en toda la industria, en muebles y de la madera 2008. ESPINOSA, Op. Cit., p.25. 
La diferencia entre el valor de la producción total por persona ocupada en promedio en toda la industria es un $202 \%$ mayor que en las industrias del mueble y de la madera. En la industria del mueble y de la madera se produce solo un $49.34 \%$ de lo que se produce en promedio en la industria mexicana en general.

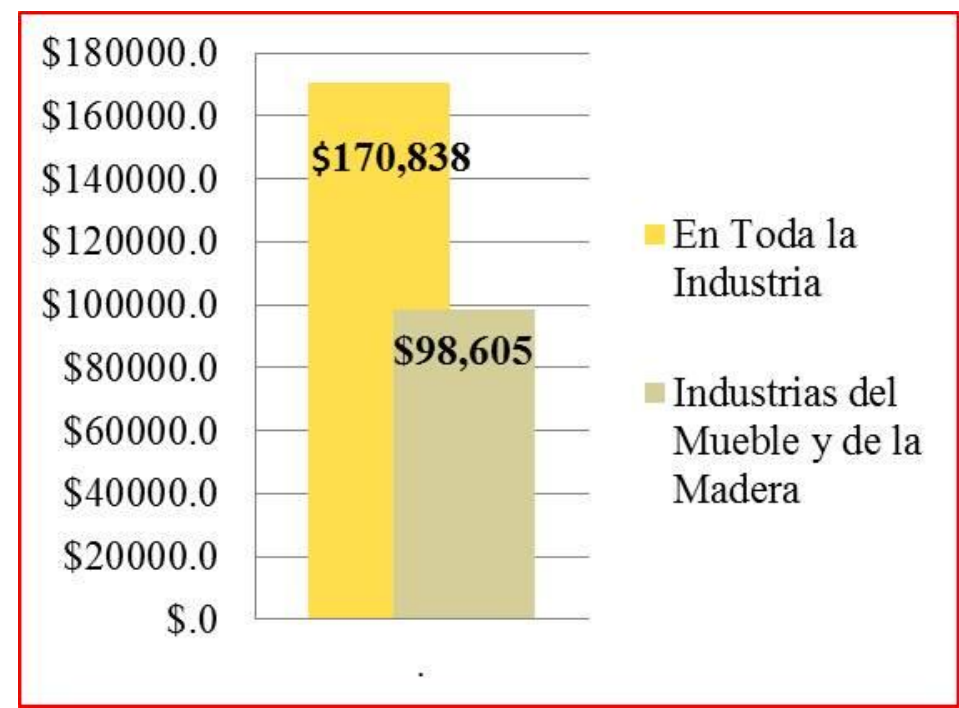

Fig.11. Remuneraciones promedio por persona en toda la industria y en muebles y de la madera 2008. ESPINOSA, Op. Cit., p. 25 .

Las remuneraciones promedio por persona en toda la industria son un $173 \%$ mayor que en las industrias del mueble y de la madera, en las que el personal percibe solo un 57.71\% del promedio en toda la industria. Si la producción en las industrias del mueble y de madera es de tan solo el $49.34 \%$ de lo que se produce en promedio en toda la industria, entonces las remuneraciones deben ser menores.

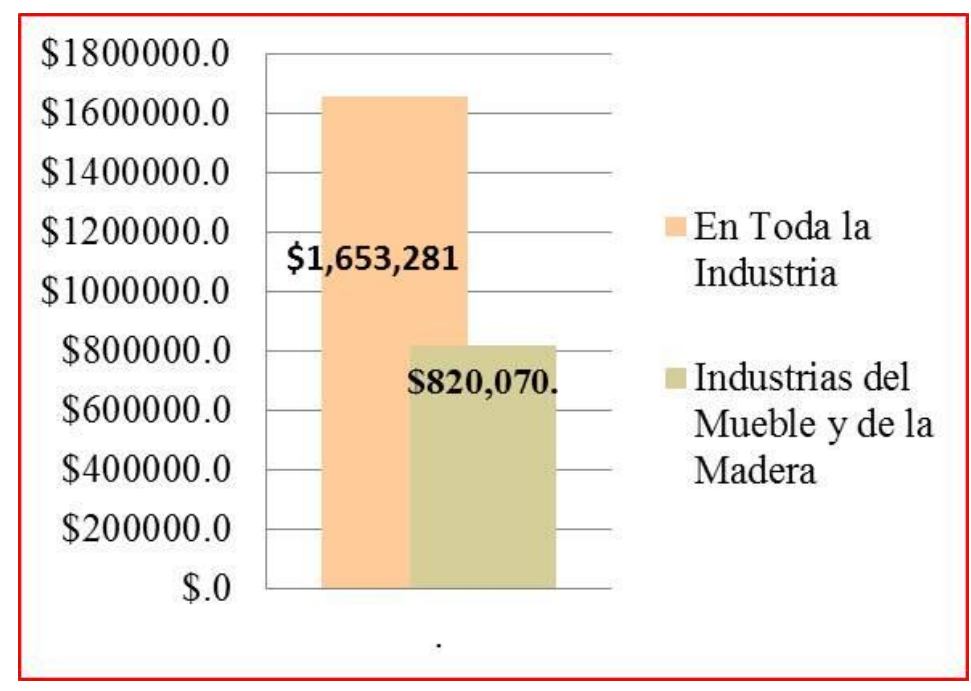

Fig. 12. Los insumos totales por persona ocupada 2008. ESPINOSA, Op. Cit., p. 26.

Los insumos totales por persona son $201.60 \%$ mayores en toda la industria que en las industrias del mueble y de la madera, esto es, en las industrias del mueble se utilizan $49.60 \%$ menos insumos que el promedio usado en toda la industria. Si la producción en las industrias del mueble y de la madera fue de un $49.34 \%$ de lo que se produce en toda la industria, es lógico que los insumos totales en el mueble y en la madera sean un $49.6 \%$ del total. 


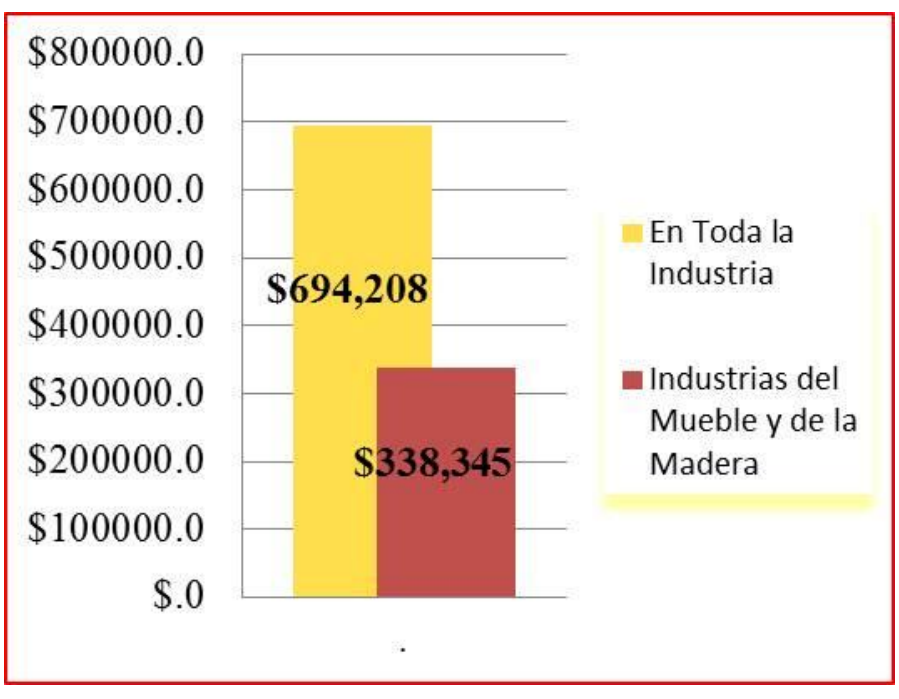

Fig. 13. Valor agregado bruto por persona. ESPINOSA, Op. Cit., p. 26.

La baja eficiencia y pobre producción en la industria del mueble y la madera, explica la diferencia del valor agregado bruto por persona ocupada, que fue mayor en toda la industria un 205.17\%. En la industria de muebles y de la madera se obtiene un valor agregado del $48.73 \%$ del promedio que se logra en toda la industria mexicana.

Es relevante el comportamiento descendente del $9.16 \%$ en el número de establecimientos industriales del mueble en México del 2003 al 2008, según el INEGI en su Encuesta Industrial Anual de 2007 a 2008 y que puede observarse en una gráfica ${ }^{11}$.

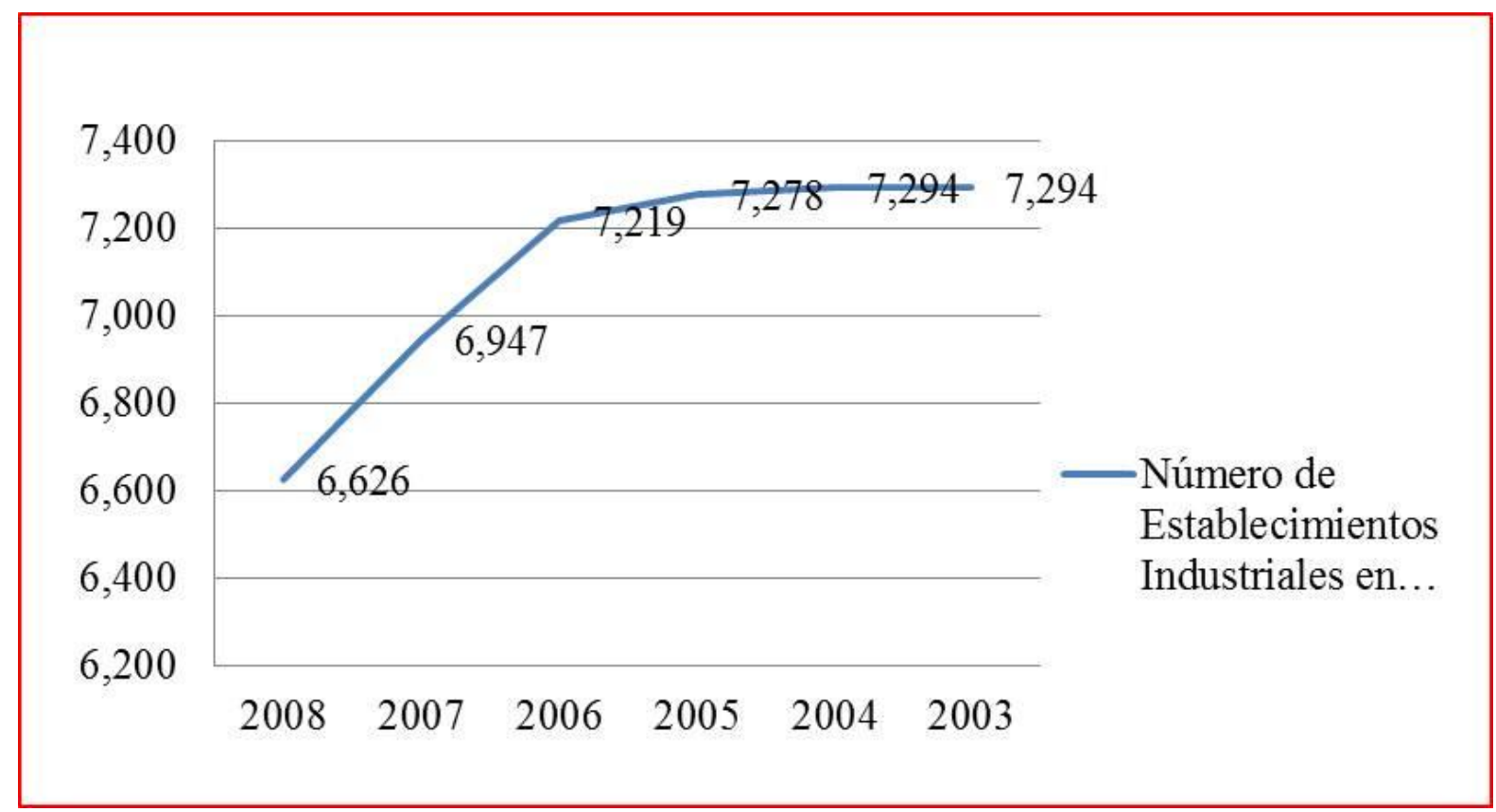

Fig. 14. Número de establecimientos comerciales en México 2003 2008. ESPINOSA, Op. Cit., p. 14. 
En cuanto a la disminución de establecimientos industriales en el subsector de la madera, se observó que alcanzó el 4.09\% el 2007 con respecto al 2008, mientras que el promedio de decrecimiento en la industria fue del $4.84 \%$; del 2003 al 2008 el descenso fue del 13.16\%.

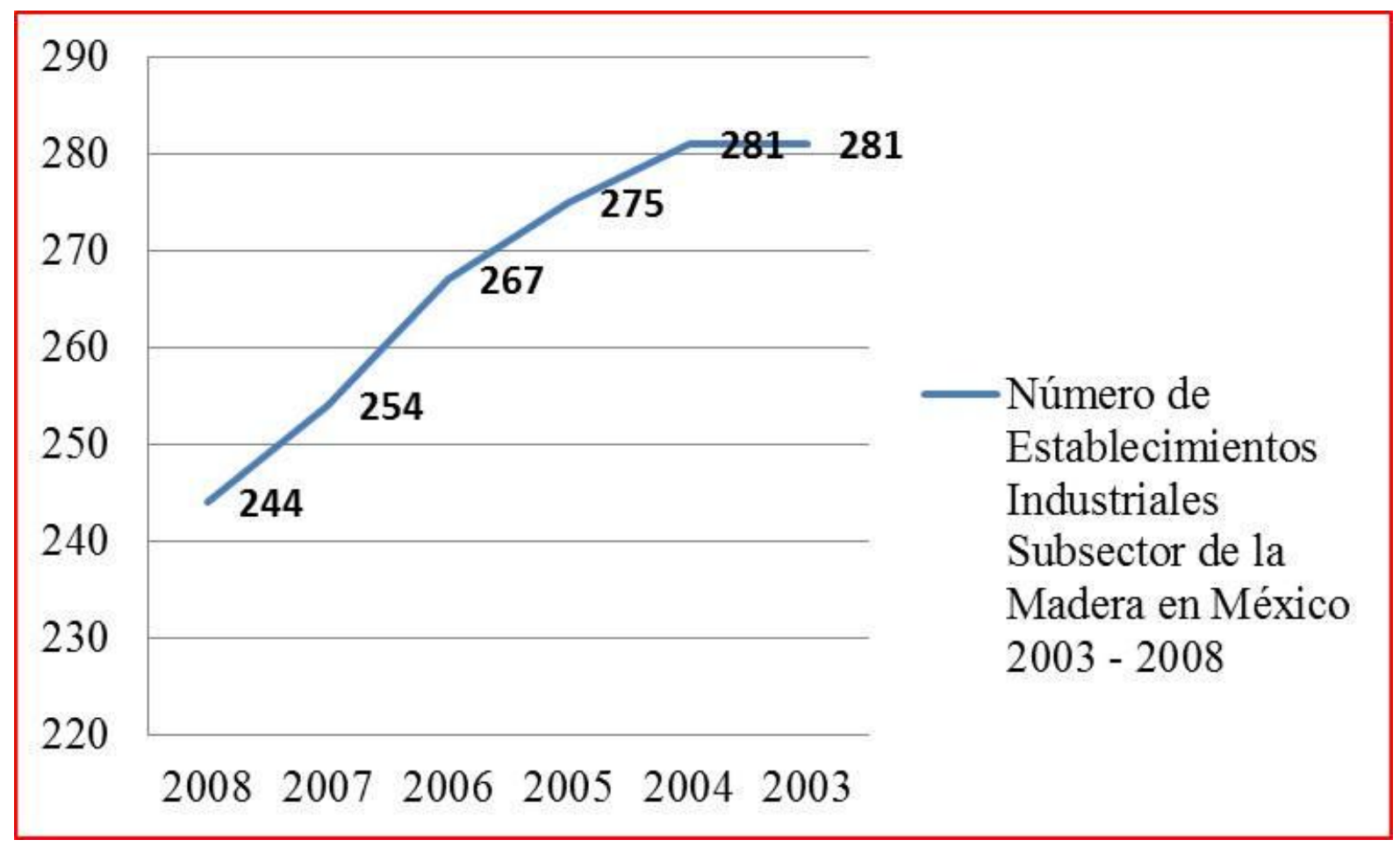

Fig. 15. Número de establecimientos industriales subsector de la madera en México 2003 a 2008. ESPINOSA, Op. Cit., p. 14.

A modo de reflexión final podemos concluir que el panorama competitivo para México en la industrialización y comercialización del mueble es difícil y su mercado interno está muy deprimido. Sin embargo, se ha demostrado en el presente y en el pasado -con altos volúmenes de exportaciones- que se puede competir globalmente entregando muebles de muy alta calidad. Es imperativo para los fabricantes y comercializadores mexicanos el acercarse a los mercados locales para identificar y satisfacer eficientemente las necesidades específicas de sus clientes potenciales, para aumentar su cuota de participación, competir contra importadores globales y revertir el decrecimiento industrial y comercial de los últimos años. Uno de los puntos fuertes industriales -y de gran importancia para resolver los problemas del sector mueblero- es la alta cualificación de la mano de obra del artesano mexicano, que data de siglos atrás, que permanece vigente y que se hace patente día a día en el maquinado, labrado y terminado de muebles finos.

\section{NOTAS}

${ }^{1}$ GOBIERNO DEL PERÚ, Perfil de Mercado y Competitividad Exportadora de Muebles de Madera (2003), recuperado el 3 de septiembre de 2012, www.minicetur.gob.pe/

${ }^{2}$ INEGI, Cuentas Nacionales Producto Interno Bruto Trimestral a Precios Corrientes Industrias 
Manufactureras (2012). Banco de Información Económica, recuperado el 13 de abril de 2012, www.inegi.org.mx/

3 INEGI, Anuario Estadístico del Comercio Exterior de los Estados Unidos Mexicanos 2011, recuperado el 13 de abril de 2012, www.inegi.org.mx/

${ }^{4}$ INEGI, Censo Económico 2004, Comercio al por menor, Instituto Nacional de Estadística y Geografía, recuperado el 2 de septiembre de 2012, www.inegi.org.mx/

5 INEGI, Estadísticas Económicas: Establecimientos comerciales, comercio al por mayor y al por menor (2010), Instituto Nacional de Estadística y Geografía, recuperado el 2 de septiembre de 2012, www.inegi.org.mx/

${ }^{6}$ Ibídem.

7 INEGI, Censo Económico 2004, Comercio al por menor, Instituto Nacional de Estadística y Geografía, recuperado el 2 de septiembre de 2012, www.inegi.org.mx/

${ }^{8} \mathrm{La}$ información se deriva de las novedades y noticas del sector que publica regularmente la revista online International Furniture and Lighting Magazine, concretamente la nota titulada "Industria del Mueble de México se reduce un $20 \%$ en 5 años", recuperado 17 de marzo de 2012, www. infurma.es/

9 INEGI, Encuesta Industrial Anual 2007-2008: 231 Clases de Actividad Económica, Instituto Nacional de Estadística y Geografía, recuperado el 2 de septiembre de 2012, www.inegi.org.mx/

10 Ibídem, recuperado el 25 de marzo de 2012, www.inegi.org.mx/

${ }^{11}$ Ibídem.

Fecha de recepción: 22 de octubre de 2012

Fecha de revisión: 9 de noviembre de 2012

Fecha de aceptación: 3 de diciembre de 2012 